Purdue University Purdue e-Pubs

2011

\title{
A microscale model for thin-film evaporation in capillary wick structures
}

\author{
Ram Ranjan \\ Purdue University - Main Campus \\ Jayathi Y. Murthy \\ Purdue University - Main Campus \\ S V. Garimella \\ Purdue University, sureshg@purdue.edu
}

Follow this and additional works at: http://docs.lib.purdue.edu/coolingpubs

Ranjan, Ram; Murthy, Jayathi Y.; and Garimella, S V., "A microscale model for thin-film evaporation in capillary wick structures" (2011). CTRC Research Publications. Paper 142.

http://dx.doi.org/doi:10.1016/j.ijheatmasstransfer.2010.09.037

This document has been made available through Purdue e-Pubs, a service of the Purdue University Libraries. Please contact epubs@purdue.edu for additional information. 


\title{
A Microscale Model for Thin-Film Evaporation in Capillary Wick Structures ${ }^{\ddagger}$
}

\author{
Ram Ranjan, Jayathi Y. Murthy and Suresh V. Garimella ${ }^{\S}$ \\ School of Mechanical Engineering and Birck Nanotechnology Center \\ Purdue University \\ 585 Purdue Mall, West Lafayette, Indiana 47907 USA
}

\section{ABSTRACT}

A numerical model is developed for the evaporating liquid meniscus in wick microstructures under saturated vapor conditions. Four different wick geometries representing common wicks used in heat pipes, viz., wire mesh, rectangular grooves, sintered wicks and vertical microw ires, are modeled and compared for evaporative performance. The solid-liquid combination considered is copper-water. Steady evaporation is modeled and the liquid-vapor interface shape is assumed to be static during evaporation. Liquid-vapor interface shapes in different geometries are obtained by solving the Young-Laplace equation using Surface Evolver. Mass, momentum and energy equations are solved numerically in the liquid domain, with the vapor assumed to be saturated. Evaporation at the interface is modeled by using heat and mass transfer rates obtained from kinetic theory. Thermocapillary convection due to non-isothermal conditions at the interface is modeled for all geometries and its role in heat transfer enhancement from the interface is quantified for both low and high superheats. More than $80 \%$ of the evaporation heat transfer is noted to occur from the thin-film region of the liquid meniscus. The very small Capillary and Weber numbers resulting from the small fluid velocities near the interface for low superheats validate the assumption of a static liquid meniscus shape during evaporation. Solid-liquid contact angle, wick porosity, solid-vapor superheat and liquid level in the wick pore are varied to study their effects on evaporation from the liquid meniscus.

Keywords: heat pipes, wick structure, evaporation, thin film, electronics cooling, meniscus

\footnotetext{
${ }^{\ddagger}$ Submitted for publication in International Journal of Heat and Mass Transfer, May 2010, and in revised form August 2010

$\S$ Author to whom correspondence should be addressed: 765-494-5621, sureshg@purdue.edu
} 


\section{NOMENCLATURE}

\begin{tabular}{|c|c|}
\hline$A$ & area $\left(\mathrm{m}^{2}\right)$ \\
\hline$A^{*}$ & Hamaker constant \\
\hline Bo & Bond number $\left(B o=\rho g L^{2} / \sigma\right)$ \\
\hline$C_{P}$ & specific heat $\left(\mathrm{J} / \mathrm{kg}^{\circ} \mathrm{C}\right)$ \\
\hline $\mathrm{Ca}$ & Capillary number $(\mu V / \sigma)$ \\
\hline$d$ & $\begin{array}{l}\text { width of rectangular ribs, or diameter } \\
\text { of sphere/wire (m) }\end{array}$ \\
\hline$d_{i n t}$ & $\begin{array}{l}\text { width/diameter of the intersection } \\
\text { area between wires/particles of two }\end{array}$ \\
\hline & layers due to sintering (m) \\
\hline$g$ & acceleration due to gravity $\left(\mathrm{m} / \mathrm{s}^{2}\right)$ \\
\hline$h$ & initial height of liquid free surface \\
\hline & from bottom surface (m) \\
\hline$h_{\text {evap }}$ & convection heat transfer coefficient \\
\hline & defined for evaporation $\left(\mathrm{W} / \mathrm{m}^{2} \mathrm{~K}\right)$ \\
\hline$h_{f g}$ & latent heat of evaporation $(\mathrm{J} / \mathrm{kg})$ \\
\hline$h_{n a t}$ & heat transfer coefficient for natural \\
\hline & convection $\left(\mathrm{W} / \mathrm{m}^{2} \mathrm{~K}\right)$ \\
\hline$h_{l}$ & liquid enthalpy (J) \\
\hline$H$ & dimensionless height of liquid free \\
\hline & surface $(=h / L)$ \\
\hline$k$ & thermal conductivity $(\mathrm{W} / \mathrm{m} \mathrm{K})$ \\
\hline$l$ & length of wires/ribs in unit cell (m) \\
\hline$L$ & characteristic length (m) \\
\hline$\dot{m}^{\prime \prime}$ & evaporative mass flux $\left(\mathrm{kg} / \mathrm{m}^{2} \mathrm{~s}\right)$ \\
\hline $\bar{M}$ & molecular weight (kg/kmol) \\
\hline$M a$ & Marangoni number \\
\hline & $\left((d \sigma / d T)(\nabla T) L^{2}(1 / \mu \alpha)\right)$ \\
\hline
\end{tabular}

$\mathrm{Nu} \quad$ Nusselt number $\left(h_{n a t} L / k\right)$ $\begin{array}{ll}p^{\prime} & \text { pitch }(\mathrm{m}) \\ p & \text { hydrodynamic pressure }(\mathrm{Pa}) \\ P e & \text { Peclet number }(\mathrm{Pe}=\operatorname{Re} \mathrm{Pr}) \\ P r & \text { Prandtl number } \\ r & \text { radius of wires/spheres }(\mathrm{m}) \\ R e & \text { Reynolds number }(\operatorname{Re}=\rho V L / \mu) \\ \bar{R} & \text { universal gas constant }(\mathrm{J} / \mathrm{mol} \mathrm{K}) \\ R^{*} & \text { asymptotic radius of liquid meniscus }\end{array}$ (m)

$R a \quad$ Rayleigh number $\left(R a=\left(g \beta\left|T_{\text {wall }}-T_{v}\right| d^{3} \operatorname{Pr}\right) / v^{2}\right)$

$S_{M} \quad$ mass source term $\left(\mathrm{kg} / \mathrm{m}^{3} \mathrm{~s}\right)$

$S P \quad$ square-packed configuration

$T \quad$ temperature $(\mathrm{K})$

$V \quad$ velocity $(\mathrm{m} / \mathrm{s})$

We Weber number $\left(\rho V^{2} L / \sigma\right)$

\section{Greek}

$\alpha \quad$ thermal diffusivity $\left(\mathrm{m}^{2} / \mathrm{s}\right)$

$\beta \quad$ thermal expansion coefficient $(1 / \mathrm{K})$

$\delta \quad$ thin-film thickness (m)

$\sigma \quad$ liquid-vapor surface tension $(\mathrm{N} / \mathrm{m})$

$\rho \quad$ density of liquid $\left(\mathrm{kg} / \mathrm{m}^{3}\right)$

$\theta \quad$ contact angle between liquid and solid surface

$v \quad$ kinematic viscosity $\left(\mathrm{m}^{2} / \mathrm{s}\right)$

$\mu \quad$ dynamic viscosity $\left(\mathrm{Ns} / \mathrm{m}^{2}\right)$

$\hat{\sigma} \quad$ accommodation coefficient

\section{Subscripts}

bot bottom solid wall 


$\begin{array}{llll}c & \text { capillary pressure } & l v & \text { liquid-vapor interface } \\ \text { cell } & \text { cell element } & \max & \text { maximum } \\ d & \text { disjoining pressure } & \text { sat } & \text { saturation } \\ \text { equ } & \text { equilibrium } & \text { ref } & \text { reference } \\ f & \text { face of cell element } & v & \text { vapor } \\ l & \text { liquid } & \text { wall } & \text { non-wet portion of the solid wall }\end{array}$

\section{INTRODUCTION}

Heat pipes have proven to be among the most efficient passive cooling devices for electronics cooling. Heat pipes use a porous medium to wick fluid from the condenser to the evaporator section. Wicking is caused by capillary forces acting at the solid-liquid-vapor contact line in the liquid-filled interstices in the porous medium. With the increasing power density of electronic components, there is a need to optimize heat pipe microstructures to maximize the heat transfer rate and to minimize thermal resistance. The wicking and thin-film evaporation characteristics of diverse wick microstructures were recently investigated by the authors $[1,2]$. Four different wick microstructures were modeled us ing Surface Evolver [3] and static liquid-meniscus shapes were obtained for different wick geometries and solid-liquid contact angles. A sintered wick structure was found to provide the greatest wicking capability as well as the highest rate of thin-film evaporation. These conclusions were drawn on the basis of static liquid meniscus shapes, without flow and heat transfer computations. In the present work, evaporation heat transfer from the liquid-vapor interface in different wick structures is modeled under the saturated vapor conditions representative of actual heat pipe operating conditions. The flow field established in the wick pore due to evaporation at the liquid-vapor interface is mode led and evaporation heat transfer rates are computed for common microstructures.

Iverson et al. [4] experimentally quantified wick performance in terms of evaporation rates for sintered copper powder wicks under conditions simulating heat pipe operation. They compared the performance of four sintered wick samples of different pore sizes. The evaporative thermal resistance across thin layers of sintered copper wicks of different porosities was experimentally measured under saturated vapor conditions by Davis and Garimella [5]. Thin-film evaporation, which takes place near a solid-liquid-vapor junction, is believed to be the dominant mode of heat transfer in such systems. Thinfilm evaporation has been reported to affect the overall heat transfer capability in sintered porous media [6]. A theoretical model for thin-film evaporation was developed by Wang et al. [7, 8]. The model predicts that more than $50 \%$ of the total heat transfer from the evaporating meniscus occurs in the micro region of the meniscus. 
Evaporation from liquid menisci in simple wicking geometries has been studied in the literature $[9,10]$ using mathematical models. Wang et al. [11] modeled the transport from a volatile meniscus inside an open microtube. This work delineated the structure of fluid flow near an evaporating meniscus, inc luding Marangoni and buoyancy-driven instabilities. Recently, Dhavaleswarapu et al. [12] visualized flow patterns near an evaporating meniscus using $\mu \mathrm{PIV}$ techniques and compared the influence of buoyancy and thermocapillarity on the overall flow structure. These studies have led to a better understanding of the physics of an evaporating liquid meniscus and serve to provide guidelines for the design of efficient microstructures for passive cooling devices.

Non-uniform evaporation at a liquid-vapor interface leads to the generation of thermocapillary stresses along the interface. As a result, thermocapillary vortices are formed near the interface due to Marangoni convection. This causes better mixing and increased heat transfer rates. Marangoni convection under large temperature differences has been shown to have a significant enhancement effect on heat transfer $[13,14,15]$. Khrustalev and Faghri [16] developed a mathematical model of the evaporating liquid-vapor meniscus in a capillary slot. They concluded that fluid flow can increase the heat transfer by up to $30 \%$. However, only a 3-5\% increase was reported for superheats below $5 \mathrm{~K}$. Diffusion-driven evaporation from a liquid-vapor interface in a capillary slot has been modeled by Wang et al. [11] and Rice et al. [17].

Evaporation rates from the liquid meniscus in wick microstructures must be predicted for optimizing the wick topology and geometry in passive cooling devices. In the present work, evaporation from the liquid-vapor interface in two- and three-dimensional wick microstructures is modeled under the following assumptions:

1. The vapor phase above the liquid-vapor interface is assumed to be saturated to match the working conditions inside a heat pipe.

2. The liquid meniscus is assumed to be static during the evaporation process, which is reasonable when the rate of feeding flow is sufficient to support the rate of evaporation at the interface.

3. The effects of disjoining pressure and capillary pressure on the rate of evaporation from the liquidvapor interface formed inside wick pores have not been modeled in this work. These effects are insignificant for length scales (or wick dimensions) $>100 \mu \mathrm{m}$, as shown by Wang et al. [7]. They showed that the contribution of the thin-film region to the net heat transfer rate from a liquid meniscus formed inside a rectangular channel of width $122 \mu \mathrm{m}$ was only $8 \%$. (The thin film region, according to the ir definition, is that portion of the meniscus in which intermolecular forces such as dis joining pressure are significant.) For larger channel widths, this contribution was shown to be smaller than $5 \%$. Since the typical dimension of capillary wick structures used in heat pipes is 100- 
$200 \mu \mathrm{m}$, the effects of intermolecular forces on evaporation heat transfer rate from the liquid meniscus is assumed not to be significant and hence omitted from the present model.

A comparative study of four different well-defined microstructured surfaces, representing sintered wicks, vertical microwires, rectangular grooves and screen mesh, is performed. The solid-liquid combination selected is copper-water. The microstructure with the best performance for the evaporator section of a heat pipe is determined from these computations. Non-isothermal evaporation at the liquidvapor interface, leading to Marangoni convection near the interface, is also studied. The parameters affecting the rate of evaporation from wick microstructures, viz., wick geometry, porosity, superheat, solid-liquid contact angle and meniscus level in the wick pore, are varied and their effects on evaporation rate are presented. The role of thin-film evaporation and Marangoni convection in the heat transfer performance of a wick is also determined. Results from the present work contribute to the understanding of the micro-level physics of evaporation in wick structures which can then be incorporated into an improved numerical model for working of heat pipes [18].

\section{MATHEMATICAL MODEL}

\subsection{Problem Description}

\subsubsection{Microstructure topologies}

Some of the common wick structures used in cooling devices are made of wire meshes, sintered powders, grooves and felt/fiber. These microstructures are generally multi-layered. In this work, evaporation from the liquid free surface formed at the top of the wick pores is modeled for the four geometries studied so as to compare their evaporative performance. The porosity, defined as the ratio of void volume to the total volume, is taken to be same in all four cases. As defined in [2], the unit cells for the four surfaces are shown in Figure 1 and described below.

Topology 1: Uniform spheres on a surface in square packing (SP) arrangement (Figure 1 (a) and (b)). Topology 2: Surface with vertical wires in square packing (SP) arrangement (Figure 1 (c) and (b)). Topology 3: Surface with parallel horizontal wires (Figure 1 (a) and (d)).

Topology 4: Surface with parallel horizontal rectangular ribs (Figure 1 (c) and (d)).

In Figure 1 (a), $h$ is the initial height of the filling liquid measured from the bottom, and $r$ is the radius of the wire or sphere. $h$ is defined as the height of the meniscus ins ide the wick pore in a nonequilibrium situation, i.e., when the meniscus in the wick pore is flat. This is also the initial configuration of the meniscus prescribed in Surface Evolver to obtain the equilibrium minimum-energy shape of the liquid meniscus for a given solid-liquid contact angle. In Figure 1(d), the length, $l$, of the wires and ribs is not significant as the problem is two-dimensional in those cases. The pitch, $p$ ', is defined as the distance between the centers of adjacent spheres/wires/ribs. In the cases of square-packed spheres and wires, we 
assume that the pitch is the same in both the longitudinal and transverse directions. The same porosity is maintained for all other topologies considered in the comparative study for evaporative performance. The non-dimensional meniscus level is defined as $H=h / r$.

\subsubsection{Liquid meniscus shapes}

Static liquid meniscus shapes in the given wick geometries are obtained using the program Surface Evolver [3]. Surface Evolver computes the total surface energy of a given system and the equilibrium minimum energy configuration is obtained by a gradient-descent method. Details of this method can be found in $[1,2]$. The static liquid meniscus shapes are exported from Surface Evolver to GAMBIT [19] and the domain is discretized for finite volume computations in FLUENT [19]. It is noted that the assumption of a static meniscus shape under evaporative conditions would be valid for very small Weber and Capillary numbers, and the validity of this assumption will be discussed in section 4.3.6. Gravitational forces are not included in the Surface Evolver or CFD computations. The Bond number, defined as the ratio of gravitational to surface tension forces $\left(B o=\rho g L^{2} / \sigma\right)$, is of the order of $10^{-3}$ for microstructures of length scales of the order of $100 \mu \mathrm{m}$ and a solid-liquid combination of copper and water. The surface tension forces are thus much more significant than any other forces at this length scale. The porosity of the wick (a porous medium) is defined as the ratio of liquid (or void) volume to the total volume of a unit cell (Figure 1) representing the porous medium. The porosity of all the microstructures is fixed at 0.56 , while the characteristic length scale of the wick, i.e., diameter in case of wires and spheres, and rib width in case of rectangular grooves, is held at $200 \mu \mathrm{m}$.

Figure 2 (a) shows the equilibrium shape of a liquid meniscus formed inside the pore of squarepacked spheres on a surface. The solid-liquid contact angle is assumed to be $30^{\circ}$, the porosity is 0.56 , and the non-dimensional radius (radius taken as the length scale) of the spheres is 1 . The surface mesh, obtained from Surface Evolver, is exported into GAMBIT and a finite-volume mesh is generated. Tetrahedral elements are used for meshing the liquid and solid domains. The mesh generated for the case of square-packed uniform spheres with a porosity of $0.56, H=1$ and solid-liquid contact angle $=30^{\circ}$ is shown in Figure 2(b). Only one-fourth of the pore surrounding a single sphere is modeled, exploiting the symmetry planes.

\subsection{Evaporation at the Liquid-Vapor Interface}

Evaporation from a liquid-vapor interface has been modeled under the assumption of saturated vapor conditions, simulating heat pipe operation. The evaporative mass flux at the interface is obtained according to Schrage [20]: 


$$
\dot{m}^{\prime \prime}=\frac{2 \hat{\sigma}}{2-\hat{\sigma}}\left(\frac{\bar{M}}{2 \pi \bar{R}}\right)^{1 / 2}\left(\frac{p_{v_{-} e q u}\left(T_{l v}\right)}{T_{l v}^{1 / 2}}-\frac{p_{v}}{T_{v}^{1 / 2}}\right)
$$

The equilibrium vapor pressure can be approximated as the corresponding saturation pressure, $p_{v_{-} e q u}\left(T_{l v}\right)=p_{s a t}\left(T_{l v}\right)$, which in turn is given by

$$
p_{s a t}\left(T_{l v}\right)=p_{\text {sat_ref }} \exp \left(\frac{\bar{M} h_{f g}}{\bar{R}}\left(\frac{1}{T_{\text {sat_ref }}}-\frac{1}{T_{l v}}\right)\right)
$$

\subsection{Governing Equations and Boundary Conditions}

\section{Liquid domain}

Incompressible, laminar and steady flow of water with constant properties is assumed in the

liquid domain. The follow ing continuity, momentum and energy equations are solved:

$$
\begin{gathered}
\nabla \cdot \vec{V}=0 \\
0=-\nabla p+\nabla \cdot\left(\mu_{l} \nabla \vec{V}\right)-\rho_{l} \vec{V} \cdot \nabla \vec{V} \\
0=-\rho_{l} \vec{V} \cdot \nabla\left(h_{l}\right)+\nabla \cdot\left(k_{l} \nabla T\right)
\end{gathered}
$$

In the solid wall, the energy equation reduces to:

$$
\nabla^{2} T=0
$$

The boundary conditions are illustrated below for the case of a 2D meniscus formed between horizontal wires as shown in Figure 3.

\section{Liquid inlet}

The incoming liquid is assumed to be at a constant temperature, $T_{\text {inlet }}$, with a stagnation-pressure inlet boundary condition.

\section{Bottom wall}

A constant temperature boundary condition is applied at the bottom solid wall. In a sintered wick structure, neighboring particles/wires are attached over a certain contact area. In the present work, only the top layer of the wick structure is considered, and the intersection area with the lower layers of particles/wires is represented by a bottom wall with the assumption of a contact area width or diameter of $0.1 * d$. The temperature of the bottom wall is represented by $T_{b o t}$.

\section{Top wall}

A convective heat transfer boundary condition is imposed on the non-wetted portion of the solid particles which is exposed to vapor, labeled Top Wall in Figure 3:

$$
-k_{\text {wall }} \nabla T . \vec{n}=h_{\text {nat }}\left(T_{\text {wall }}-T_{v}\right)
$$

The value of the natural convection coefficient $h_{n a t}$ from the surface of spheres and long wires is given by: 


$$
h_{n a t}=\frac{k}{d} N u
$$

in which the Nusselt number, $N u$, is given by [21]:

$$
\begin{gathered}
N u=\left(0.6+\frac{0.387 R a^{1 / 6}}{\left(1+(0.559 / \operatorname{Pr})^{9 / 16}\right)^{8 / 27}}\right)^{2} \\
R a=\left(g \beta\left|T_{\text {wall }}-T_{v}\right| d^{3} \operatorname{Pr}\right) / v^{2}
\end{gathered}
$$

For a wire of diameter $=200 \mu \mathrm{m}$ and $T_{\text {wall }}-T_{v}=2.5 \mathrm{~K}, h_{\text {nat }} \approx 38 \mathrm{~W} / \mathrm{m}^{2} \mathrm{~K}$. This value of $h_{\text {nat }}$ has been used for all microstructures in the present work, unless otherwise specified.

\section{Liquid-vapor interface}

The liquid-vapor interface is modeled as a fixed interface with a convective boundary condition; $h_{\text {evap }}$ is obtained using the evaporative mass flux expression (Eqn. 1) and is discussed further in the following section.

\section{NUMERICAL ANALYSIS}

The numerical solution is obtained with the pressure-based finite volume scheme $[22,23]$ using the commercial CFD package, FLUENT [19]. The convective and diffusive terms in the momentum and energy equations were discretized using the second-order upwind scheme and the second-order differencing scheme, respectively. Pressure-velocity coupling is achieved using the SIMPLE algorithm. Grids for all microstructures considered are generated using tetrahedral elements. Only the unit cell representations shown in Figure 1 are included in the domain. Mass transport due to evaporation at the liquid-vapor interface is implemented by imposing mass source terms in the liquid cells adjacent to the interface, as represented in Figure 4. This mass source term has a negative value and is given by:

$$
S_{M}=-\dot{m} " A_{f} / V_{\text {cell }}
$$

where $A_{f}$ is the interface area of the cell and $V_{\text {cell }}$ is the volume of the cell. The evaporative heat transfer corresponding to the evaporation rate in Eqn. 1 is implemented as an effective convective heat transfer condition at the liquid-vapor interface, with a convective heat transfer coefficient given by

$$
h_{\text {evap }}=\frac{\dot{m} " h_{f g}}{\left(T_{l v}-T_{v}\right)}
$$

This ensures that an evaporative heat loss $\dot{m} h_{f g}$ occurs from the liquid at the vapor-liquid interface. 


\section{RESULTS AND DISCUSSION}

The numerical model is first verified against the semi-analytical model for thin-film evaporation from a liquid meniscus developed by Wang et al. [7]. Evaporation from liquid menisci formed in four different wick microstructures are then considered. Feeding flow and temperature fields are first presented for the 2D meniscus formed between horizontal wires and for 3D menisci formed in a layer of packed spheres and vertical microwires. All four microstructures are then compared for their evaporative performance for a fixed porosity and characteristic length. The influence of pore geometry, characteristic length, wick porosity, solid-liquid contact angle, vapor temperature, and imposed superheat $\left(\Delta T=T_{b o t}-T_{v}\right)$ is then discussed with reference to a $2 \mathrm{D}$ liquid meniscus formed between horizontal wires. A watercopper combination is used in all the simulations, unless specified. Thermophysical properties of water are included in Table 1.

\subsection{Model Verification}

The evaporation heat transfer rate from a liquid meniscus formed in a rectangular slot is computed using the present numerical model and compared with the results of Wang et al. [7], who investigated an evaporating meniscus of octane in a microchannel through an augmented Young-Laplace model and the kinetic theory-based expression (Eqn. 1) for mass transport across the liquid-vapor interface. The equilibrium vapor pressure at the liquid-vapor interface is given by

$$
p_{v_{-} e q u}\left(T_{l v}\right)=p_{s a t}\left(T_{l v}\right) \exp \left[\frac{p_{v_{-} e q u}\left(T_{l v}\right)-p_{s a t}\left(T_{l v}\right)-\left(p_{d}+p_{c}\right)}{\rho_{l} T_{l v} \bar{R} / \bar{M}}\right]
$$

where $p_{d}\left(=-A^{*} / \delta^{3}\right)$ and $p_{c}\left(=2 \sigma / R^{*}\right)$ are the disjoining and capillary pressures, respectively. They mode led the effects of disjoining pressure and capillary pressure on the thin-film profile and evaporation heat transfer rate. The liquid pressure drop in the thin liquid film was approximated based on lubrication theory. For verifying the present model, a case with an asymptotic meniscus radius $\left(R^{*}\right)$ of $61 \mu \mathrm{m}$ was chosen, with a meniscus profile identical to that in Wang et al. [7]. The domain for this problem is shown in Figure 5(a). The thickness of the non-evaporating thin-film is taken to be $3.4 \mathrm{~nm}$. The vapor is assumed to be saturated at $343 \mathrm{~K}$ while the hot wall is superheated at $344 \mathrm{~K}$. The thermophysical properties of octane were taken from [7]. Figure 5(b) shows the temperature contours in the liquid domain of the evaporating meniscus. Figure 6 shows the evaporative mass flux and cumulative heat transfer rate along the meniscus, starting from the non-evaporating thin-film region. More than $50 \%$ of total evaporation heat transfer occurs from a meniscus region with thickness below $1 \mu \mathrm{m}$, in agreement with Wang et al. The present numerical model predicts the total evaporation heat transfer rate from the meniscus to be $1.92 \mathrm{~W} / \mathrm{m}$ in contrast to the $1.69 \mathrm{~W} / \mathrm{m}$ predicted by Wang et al. [7]. The suppression of evaporation heat transfer due to dis joining and capillary pressures are also modeled and found to be 
insignificant, with less than $1 \%$ change in the evaporation rate due to equilibrium vapor pressure supression at the interface. However, the present model does not approximate the liquid pressure drop inside the liquid thin-film by lubrication theory, and therefore predicts an evaporation heat transfer rate that is higher by $\sim 13 \%$ as compared to Wang et al.. It should be noted that the lubrication theory approximation made by Wang et al. fails for large channel widths.

\subsection{Comparison of Wick Microstructures}

A comparative study of evaporation from the liquid menisci formed in different wick microstructures is presented in this section.

\subsubsection{Feeding flow and temperature fields}

Figure 7(a) shows the steady-state temperature field in the liquid and solid domains along with the particle paths at a liquid cross-section during evaporation from a static meniscus between horizontal wires for $d=200 \mu \mathrm{m}, T_{b o t}=T_{\text {inlet }}=300.5 \mathrm{~K}, T_{v}=298 \mathrm{~K}, \theta=15^{\circ}$ and $p^{\prime}=356 \mu \mathrm{m}$. From the temperature contours, it is observed that evaporation at the liquid-vapor interface leads to cooling of the liquid near the interface relative to the incoming liquid at the inlet. Liquid is fed steadily to the interface to sustain evaporation. The particle paths illustrate the fluid feeding as well as the Marangoni vortex set up near the interface due to thermocapillary convection. Temperature contours in the wick pore between squarepacked vertical microw ires are shown in Figure 7(b) for a solid superheat $\left(T_{b o t}-T_{v}\right)$ of $2.5 \mathrm{~K}, d=200 \mu \mathrm{m}$, $T_{\text {inlet }}=T_{b o t}=300.5 \mathrm{~K}, T_{v}=298 \mathrm{~K}, \theta=60^{\circ}$ and $p^{\prime}=266 \mu \mathrm{m}$. The liquid-vapor interface is at the vapor temperature except in the contact line thin-film region.

The temperature contours and particle paths for evaporation from a 3D meniscus formed between square-packed spheres for $d=200 \mu \mathrm{m}, T_{\text {inlet }}=T_{v}=298 \mathrm{~K}, T_{b o t}=300.5 \mathrm{~K}, \theta=15^{\circ}$ and $p^{\prime}=356 \mu \mathrm{m}$ are shown in Figure 8(a). A complex toroidal-shaped Marangoni vortex is formed below the interface due to non-isothermal evaporation at the interface. Results are also shown in Figure 8(b) at two vertical planes in the wick pore, the central plane (c-d) and the symmetry plane (a-b). The temperature of the liquidvapor interface is lowest in the central pore region, away from any solid walls. The Marangoni vortex formed near the interface has a toroidal shape, with the vortex diameter being non-uniform around the sphere: the vortex diameter is largest in central plane $\mathrm{c}-\mathrm{d}$ while it is smallest in symmetry plane a-b.

\subsubsection{Comparison of evaporative performance}

The different wick topologies presented in section 2.1.1 are compared here for evaporative performance under identical poros ity $(0.56)$, characteristic length $(200 \mu \mathrm{m})$, liquid and vapor conditions. A $60^{\circ}$ solid-liquid contact angle is used for all cases with $T_{b o t}=300.5 \mathrm{~K}$ and $T_{\text {inlet }}=T_{v}=298 \mathrm{~K}$. The 
evaporative heat flux based on the base (substrate) area of the wick (i.e., the sum of the liquid inlet and bottom wall areas, Figure 3) is compared to identify the best-performing microstructure. Figure 9 shows that the packed-spheres structure offers the highest rate of evaporation and substrate heat flux among the four microstructures studied. A separate comparison study conducted for a different set of parameters (contact angle changed from $5^{\circ}$ to $90^{\circ}$, superheat $\left(T_{b o t}-T_{v}\right)$ from $1 \mathrm{~K}$ to $10 \mathrm{~K}$ ) yielded a similar result. This is also consistent with previous predictions by the authors based on a thermal resistance network model and static liquid meniscus shapes in the wick microstructure [1,2]. The thin-film area of the meniscus was reported to be highest for the case of packed spheres on a surface, based on staticequilibrium liquid meniscus shapes. This leads to the highest evaporation rate for the sintered particle structure. In the present comparative study, the area-averaged heat transfer coefficient at the interface (Eqn.12) is observed to be nearly the same for all the wick structures. The rate of evaporation, therefore, is determined by the extent of the thin-film area formed on the meniscus near the solid-liquid contact line in the wick pore.

\subsection{Evaporation from a 2d Meniscus between Wires}

Evaporation from 2D menisci formed between the horizontal wires of a screen mesh is studied in detail to demonstrate the effect of parametric variations in solid-liquid contact angle, superheat, liquid level in wick pore, characteristic length and porosity of the wick. $T_{\text {inlet }}$ is taken to be the same as $T_{b o t}$ for all the cases considered here. The superheat $(\Delta T)$ is defined as $T_{b o t}-T_{v}$.

\subsubsection{Evaporation at the interface}

The evaporative mass flux and heat transfer coefficient on the interface are plotted in Figure 10(a) and 10(b), respectively, for different contact angles and superheats $\left(d=200 \mu \mathrm{m}, T_{v}=298 \mathrm{~K}, p^{\prime}=356\right.$ $\mu \mathrm{m})$. The evaporative mass flux is highest in the corner region (near the contact line). Also, more than $80 \%$ of the total evaporation from the interface occurs from a small area (approximately $20 \%$ of the total area) of the meniscus, identified as the thin-film area. According to the definition used (as in [1]), the thickness of the thin-film region is on the order of $10 \mu \mathrm{m}$; such a region has been identified as a "micro" region in other studies [7]. Thus, thin-film evaporation accounts for most of the heat transfer from the liquid meniscus. Also, the corner region is seen to be at a higher temperature than the central meniscus region which is almost at the vapor temperature. Such non-isothermal evaporation causes thermocapillary stress along the interface which leads to the formation of Marangoni vortices. The maximum heat transfer coefficient also occurs in the corner region of the meniscus; however, the maximum value of $h_{\text {evap }}$ is only $2-5 \%$ higher than that in central region of the meniscus. Both evaporative mass flux and heat transfer coefficient increase as the superheat is increased or the contact angle is decreased. 


\subsubsection{Role of bulk convection}

Marangoni convection, which arises due to a surface tension gradient at the non-isothermal interface, has been shown to increase the heat transfer rates significantly in many systems [13-15]. At low superheats $(<5 \mathrm{~K})$, however, it is observed that Marangoni convection does not significantly affect evaporation from a liquid meniscus into a saturated vapor. The role of convection is quantified here by comparing the evaporative heat flux for a full simulation including Marangoni convection with that from a calculation where only conduction is considered in the liquid and solid domains. The Peclet number is very small (of the order of $10^{-2}$ ) for low superheats and hence, heat transfer in the liquid would be expected to be diffusion-dominated. The Marangoni number, defined as $M a=(d \sigma / d T)(\nabla T) L^{2}(1 / \mu \alpha)$, is 3.6 for the present conditions of $\Delta T=2.5 \mathrm{~K}$ and $L=200 \mu \mathrm{m}$. The evaporative mass flux at the interface is shown in Figure 11(a) for the pure conduction and Marangoni convection cases $\left(d=200 \mu \mathrm{m}, T_{v}=298\right.$ $\left.\mathrm{K}, p^{\prime}=356 \mu \mathrm{m}, \theta=15^{\circ}\right)$. Marangoni convection increases the evaporative mass flux in the central region of the meniscus. However, the total evaporation rate from the interface is only mildly enhanced by the convection induced in the bulk liquid. The role of the Marangoni vortex is to transport the heated liquid from near the solid superheated wall to the cooler interface area. However, due to the very low liquid velocities in this problem (due to low superheats), the effect of convection remains low. The effect of Marangoni convection is seen to increase if superheat is increased as shown in Figure 11(b).

\subsubsection{Influence of solid-liquid contact angle}

The solid-liquid contact angle has been demonstrated to have a significant effect on the thin-film area of a liquid meniscus $[1,2]$. Although copper-water is the solid-liquid combination considered in this work (with corresponding contact angles of $84^{\circ}$ and $33^{\circ}$ at the advancing and receding liquid fronts, respectively [24]), the contact angle is now varied to study its effect on evaporation. The contact angle changes with the solid-liquid combination in question, but also for a given material pair with changes in surface roughness and surface treatment. In Figure 12, the base heat flux is plotted for various contact angles and superheats. The contact angle is varied over a reasonable range for wetting fluids, i.e., from $5^{\circ}$ to $90^{\circ}$, with $d=200 \mu \mathrm{m}$, porosity $=0.56, T_{\text {inlet }}=T_{\text {bot }}, T_{v}=298 \mathrm{~K}$ and $H=1$. The heat flux is observed to decrease by almost $50 \%$ as the contact angle is changed from $5^{\circ}$ to $90^{\circ}$ at each of the three different superheat levels considered. Higher heat fluxes are observed for higher superheats. The area-averaged heat transfer coefficient at the interface $\left(\bar{h}_{\text {evap }}\right)$, on the other hand, does not change significantly with variations in contact angle. This shows that the increase in heat flux with decreasing contact angle is due 
to the increase in meniscus area. The evaporation heat transfer coefficient is determined by the saturation temperature and interfacial conditions, irrespective of the contact angle, and can be inferred from Eqns. 1 and 12. The strong dependence of heat flux on contact angle suggests that the addition of surfactants or other additives to decrease contact angle could yield large dividends in terms of the heat flux supported, provided that other controlling thermal resistances can be decreased.

\subsubsection{Effect of superheat and liquid level}

The driving temperature difference $(\Delta T)$ for evaporation and the dimensionless liquid meniscus level $(H)$ in the wick pore are varied to study their effects on evaporation from the interface with other factors held constant $\left(d=200 \mu \mathrm{m}\right.$, porosity $\left.=0.56, T_{\text {inlet }}=T_{b o t}, T_{v}=298 \mathrm{~K}\right) . H$ is taken to be 1 as the superheat is varied, while $\Delta T=2.5 \mathrm{~K}$ as $H$ is varied. In Figure 13(a), the base heat flux (and thus the rate of evaporation) is observed to increase with increasing $\Delta T$ with the increase being somewhat linear for $\Delta T$ $<15 \mathrm{~K}$. At higher superheats and low contact angles, the heat flux increases at a higher rate, as shown for $\theta=15^{\circ}$. The Peclet number $P e$, which is the ratio of advection of energy to the rate of its diffusion, is computed for four superheats $(5 \mathrm{~K}, 10 \mathrm{~K}, 15 \mathrm{~K}$ and $20 \mathrm{~K})$ for $\theta=15^{\circ}: P e=0.44(\operatorname{Re}=0.063), 0.7(\operatorname{Re}=$ $0.1), 0.91(\operatorname{Re}=0.13), 1.12(\operatorname{Re}=0.16)$ for $\Delta T=5,10,15$ and $20 \mathrm{~K}$, respectively. At these very low values of $R e$ and $P e$, convection effects cannot be significant. The non-linear increase in evaporation rate observed for superheats exceeding $15 \mathrm{~K}$ is most likely due to the non-linearity in the expression for evaporation rate (Eqn. 1) and the Clausius Clapeyron equation (Eqn. 2).

In Figure 13(b), the effect on evaporation of a variation in the liquid level in the wick pore is shown for three different contact angles. The non-dimensional liquid height $(H=h / r)$ is varied from 0.4 to 1.8. The total evaporation rate from the meniscus is highest when the meniscus is at its lowest level ( $H$ $=0.4$ ) and decreases as $H$ is increased. The total area of the meniscus as well as thin-film area are higher when $H<0.5[1,2]$. The variation of liquid level in the pore does not significantly affect the evaporation rate from the meniscus for $H>0.8$. This is in agreement with the predictions from a previous thermal resistance model developed by the authors [1] where the effective thermal resistance offered by the wick was found to change only by $15 \%$ as the liquid level in the pore was changed. The higher evaporation rates observed for $H<0.8$ is attributed to the proximity of the interface to the liquid inlet $\left(T_{\text {inlet }}=T_{\text {bot }}\right)$ which increases the interface temperature in the central region of the meniscus.

\subsubsection{Effect of characteristic length and wick porosity}

The effects of variations in porosity and characteristic length on evaporation are now presented. Values of $h_{n a t}$ are evaluated using Eqn. 9 as the wire diameter changes. Figure 14 shows the variation of base heat flux with increasing wire diameter for porosity $=0.56, T_{\text {inlet }}=T_{b o t}, T_{v}=298 \mathrm{~K}$ and $H=1$. The 
heat flux decreases steeply with increasing characteristic length for all superheats. For a very wire small diameter $(10 \mu \mathrm{m})$, the percentage thin-film area of the meniscus [1] is very high $(>80 \%)$ and hence the base heat flux is highest at the smallest diameter.

The influence of wick porosity is shown in Figure 15 for $d=200 \mu \mathrm{m}, \Delta T=2.5 \mathrm{~K}, T_{\text {inlet }}=T_{b o t}, T_{v}=$ $298 \mathrm{~K}$ and $H=1$. The rate of evaporation decreases with increasing porosity which is again because the thin-film area of the meniscus decreases with increasing poros ity $[1,2]$. The interface area-averaged heat transfer coefficient remains independent of the geometrical properties of the wick structure. The evaporative mass flux at the liquid-vapor interface is a function of the pressure and temperature at the interface and the vapor saturation temperature, as shown in Eqn. 1. Hence, the interface area-averaged heat transfer coefficient is not strongly influenced by the wick geometry.

\subsubsection{Validity of static meniscus shape assumption}

Evaporation-led instabilities at the liquid-vapor interface have been discussed for high evaporation rates in the literature [25]. In the present work, due to the lower superheats considered, very low flow velocities are induced in the liquid. This leads to a Capillary number (defined as the ratio of viscous to surface tension forces, $C a \equiv \mu V / \sigma$ ) of the order of $10^{-3}$ and a Weber number (defined as the ratio of inertial to surface tension forces, $\left.W e \equiv \rho V^{2} L / \sigma\right)$ of the order of $10^{-7}$. Therefore, surface tension is a much more significant force than viscous or inertial forces at the interface in the present case. Hence, the assumption of a constant meniscus shape during evaporation is justified at these low superheats.

\section{CONCLUSIONS}

A numerical model for evaporation from the liquid-vapor interface in wick microstructures is presented. Idealized unit-cell representations of four different wick microstructures - sintered wicks, vertical microwires, rectangular grooves and screen meshes - are modeled. Liquid-vapor interface shapes are obtained for different meniscus levels and solid-liquid contact angles using the program, Surface Evolver. Flow and temperature fields are presented for evaporation from the liquid-vapor interface in the wick pores under saturated vapor conditions. The different wick microstructures are compared for evaporative performance at a fixed porosity, characteristic length, solid-liquid contact angle and thermal boundary conditions. The pore formed between packed spheres offers the highest rate of evaporation which is consistent with the prediction made in previous work by the authors based on an approximate thermal resistance network model for heat transfer in the wick pore without detailed flow and heat transfer computations [1,2]. Non-isothermal evaporation leads to a surface tension gradient on the interface. This induces Marangoni convection in the liquid domain. Complex toroidal-shaped Marangoni vortices form below the meniscus. The role of Marangoni convection is, however, quite small for low 
superheats $(<5 \mathrm{~K})$. A parametric study is conducted to delineate the effects of changes in contact angle, superheat, meniscus level, characteristic length and wick porosity on the evaporation rates. The main conclusions from the parametric study are summarized below:

- Evaporation heat transfer from the liquid-vapor interface decreases with increasing contact angle due to a corresponding decrease in the thin-film area.

- Evaporation heat transfer increases with increasing superheat while it is less affected by a change in meniscus level. The increase in evaporation rate becomes nonlinear for larger superheats $(>10 \mathrm{~K})$ when convection becomes significant.

- The heat flux due to evaporation decreases with increasing wick characteristic length and porosity. This is again because of the corresponding decrease in thin-film area.

- The area-averaged heat transfer coefficient at the interface $\left(\bar{h}_{\text {evap }}\right)$ does not change significantly with varying wick geometry, superheat, meniscus level and contact angle.

\section{Acknowledgement}

Support for this work from the Defense Advanced Research Projects Agency (DARPA) and Space and Naval Warfare Systems Center (SPAWAR/SYSCEN) San Diego, CA under Contract No. N66001-08-C2001 is gratefully acknowledged.

\section{REFERENCES}

[1] R. Ranjan, J. Y. Murthy, S. V. Garimella, Analysis of the Wicking and Thin-film Evaporation Characteristics of Wick Microstructures, ASME Journal of Heat Transfer 131 (10) (2009) 101001.

[2] R. Ranjan, S. V. Garimella, J. Y. Murthy, Characterization of Microstructures for Heat Transfer Performance in Passive Cooling Devices, Proceedings of ASME Summer Heat Transfer Conference, August 10-14, 2008, Jacksonville, FL, paper no. HT2008-56170.

[3] K. A. Brakke, The Surface Evolver, Experimental Mathematics 1 (2) (1992) 141-165.

[4] B. D. Iverson, T. W. Davis, S. V. Garimella, M. T. North, S. S. Kang, Heat and Mass Transport in Heat Pipe Wick Structures, Journal of Thermophysics and Heat Transfer 21 (2) (2007) 392-404.

[5] T. W. Davis, S. V. Garimella, Thermal Resistance Measurement across a Wick Structure using a Novel Thermosyphon Test Chamber, Experimental Heat Transfer 21 (2008) 143-154.

[6] M. A. Hanlon, H. B. Ma, Evaporation Heat Transfer in Sintered Porous Media, ASME Journal of Heat Transfer 125 (2003) 644-652. 
[7] H. Wang, S. V. Garimella, J. Y. Murthy, Characteristics of an Evaporating Thin Film in a Microchannel, International Journal of Heat and Mass Transfer 50 (2007) 3933-3942.

[8] H. Wang, S. V. Garimella, J. Y. Murthy, An Analytical Solution for the Total Heat Transfer in Thinfilm Region of an Evaporating Meniscus, International Journal of Heat and Mass Transfer 51 (25-26) (2008) 6317-6322.

[9] X. Xu, V. P. Carey, Film Evaporation from a Micro-grooved Surface - An Approximate Heat Transfer Model and its Comparison with Experimental Data, Journal of Thermophysics and Heat Transfer 4 (1990) 512-520.

[10] H. B. Ma, G. P. Peterson, Temperature Variation and Heat Transfer in Triangular Grooves with an Evaporating Film, Journal ofThermophysics and Heat Transfer 11 (1997) 90-97.

[11] H. Wang, J. Y. Murthy, S. V. Garimella, Transport from a Volatile Meniscus inside an Open Microtube, International Journal of Heat and Mass Transfer 51 (2008) 3007-3017.

[12] H. K. Dhavaleswarapu, P. Chamarthy, S. V. Garimella, J. Y. Murthy, Experimental Investigation of Steady Buoyant-thermocapillary Convection near an Evaporating Meniscus, Physics of Fluids 19 (2007) 082103 (1-11).

[13] R. Savino, S. Fico, Buoyancy and Surface Tension Driven Convection around a Bubble, Physics of Fluids 18 (2006) 057104(1-14).

[14] M. Behnia, F. Stella, G. Guj, A Numerical Study of Three-dimensional Combined Buoyancy and Thermocapillary Convection, International Journal of Multiphase Flow 21 (3) (1995) 529-542.

[15] C. A. Ward, F. Duan, Turbulent Transition of Thermocapillary Flow Induced by Water Evaporation, Physical Review E 69 (2004) 056308(1-10).

[16] D. Khrustalev, A. Faghri, Fluid Flow Effects in Evaporation from Liquid-Vapor Meniscus, ASME Journal of Heat Transfer 118 (1996) 725-730.

[17] J. Rice, A. Faghri, A New Computational Method to Track a Liquid/Vapor Interface with Mass Transfer, Demonstrated on the Concentration Driven Evaporation from a Capillary Tube and the Marangoni Effect, Proceedings of ASME International Mechanical Engineering Congress and Exposition, Nov. 5-11, 2005, Orlando, FL, paper no. IMECE2005-81433.

[18] R. Ranjan, J. Y. Murthy, S. V. Garimella, U. Vadakkan, A Numerical Model for Transport in Flat Heat Pipes Considering Wick Microstructure Effects, International Journal of Heat and Mass Transfer (in review).

[19] Fluent Inc., Fluent 6.2 User's Guide, 2004.

[20] R. W. Schrage, A Theoretical Study of Interface Mass Transfer, New York: Columbia University Press, 1953. 
[21] Y. A. Cengel, Heat Transfer: A Practical Approach, WCB/McGraw-Hill, 1998.

[22] S. R. Mathur, J. Y. Murthy, A Pressure-based Method for Unstructured Meshes, Numerical Heat Transfer 31(2) (1997) 195-216.

[23] J. Y. Murthy, S. R. Mathur, A Conservative Numerical Scheme for the Energy Equation, ASME Journal of Heat Transfer 120 (1998) 1081-1085.

[24] V. G. Stepanov, L. D. Volyak, Y. V. Tarlakov, Wetting Contact Angles of Certain Systems, Journal of Engineering Physics and Thermophysics 32 (6) (1977) 646-648.

[25] C. Buffone, K. Sefiane, W. Easson, Marangoni-driven Instabilities of an Evaporating Liquid-vapor Interface, Physical Review E 71 (2005) 056302 (1-8). 


\section{LIST OF TABLES}

Table 1. Thermophysical properties of water at $298 \mathrm{~K}$.

\section{LIST OF FIGURES}

Figure 1. Side views of surface with (a) spheres (square packed) and horizontal wires, (c) vertical wires and parallel rectangular ribs, and plan views of surface with (b) spheres and wires (both square packed) and (d) horizontal wires and rectangular ribs. The corresponding unit cell is also shown in each case.

Figure 2. (a) Liquid meniscus shape for square-packed spheres, $H=1, d=1, \theta=15^{\circ}$; (b) surface mesh generated from GAMBIT for a unit cell representing square-packed spheres, porosity $=0.56, H=1, d=1$ and $\theta=30^{\circ}$.

Figure 3. Illustration of boundary conditions for 2D liquid meniscus formed between horizontal wires.

Figure 4. Implementation of evaporative cooling at liquid-vapor interface. A computational cell at the interface is shown.

Figure 5. (a) Computational domain used for model validation, octane meniscus is formed inside a microchannel with $R^{*}=61 \mu \mathrm{m}$; (b) temperature contours in the domain for superheat $=1 \mathrm{~K}$ (wall temperature $=344 \mathrm{~K}$ and vapor temperature $=343 \mathrm{~K}$ )

Figure 6. Evaporative mass flux and cumulative heat transfer rate at the octane meniscus formed in microchannel.

Figure 7. (a) Temperature contours and particle paths for 2D meniscus formed between horizontal wires, $d=200 \mu \mathrm{m}, T_{\text {inlet }}=300.5 \mathrm{~K}, T_{v}=298 \mathrm{~K}, T_{b o t}=300.5 \mathrm{~K}, p^{\prime}=356 \mu \mathrm{m}$ (porosity $=$ 0.56 ) and (b) square-packed vertical microw ires, $d=200 \mu \mathrm{m}, T_{\text {inlet }}=298 \mathrm{~K}, T_{v}=298 \mathrm{~K}$, $T_{b o t}=300.5 \mathrm{~K}$ and $p^{\prime}=218 \mu \mathrm{m}$ (porosity $=0.56$ ).

Figure 8. Temperature contours and particle paths for (a) 3D meniscus formed between squarepacked spheres, $d=200 \mu \mathrm{m}, T_{\text {inlet }}=298 \mathrm{~K}, T_{v}=298 \mathrm{~K}, T_{b o t}=300.5 \mathrm{~K}, p^{\prime}=356 \mu \mathrm{m}$ (porosity $=0.56$ ) and (b) central $(c-d)$ and narrow $(a-b)$ planes.

Figure 9. Comparison of microstructures for evaporative performance, porosity $=0.56, \theta=60^{\circ}$, $T_{\text {inlet }}=T_{\text {bot }}=300.5 \mathrm{~K}, T_{v}=298 \mathrm{~K}$.

Figure 10. (a) Evaporative mass flux and (b) heat transfer coefficient on the interface, $d=200 \mu \mathrm{m}$, $T_{v}=298 \mathrm{~K}, p^{\prime}=178 \mu \mathrm{m}$ (poros ity $=0.56$ ).

Figure 11. (a) Evaporative mass flux from the interface for pure conduction and bulk convection cases for different superheats, and (b) percentage change in total heat flux with and without Marangoni convection as a function of superheat, $d=200 \mu \mathrm{m}, T_{v}=298 \mathrm{~K}, p^{\prime}=$ $178 \mu \mathrm{m}$ (porosity $=0.56$ ).

Figure 12. Variation of heat flux (based on substrate area) with solid-liquid contact angle, for three different superheats, $d=200 \mu \mathrm{m}, T_{v}=298 \mathrm{~K}, p^{\prime}=178 \mu \mathrm{m}$ (porosity $=0.56$ ).

Figure 13. Variation of base heat flux with (a) superheat, $d=200 \mu \mathrm{m}, T_{\text {inlet }}=T_{b o t}, T_{v}=298 \mathrm{~K}, p^{\prime}=$ $178 \mu \mathrm{m}$ (porosity $=0.56$ ), $H=1$ and (b) meniscus level $(H), d=200 \mu \mathrm{m}, T_{\text {inlet }}=T_{\text {bot }}=$ $300.5 \mathrm{~K}, T_{v}=298 \mathrm{~K}, p^{\prime}=178 \mu \mathrm{m}$ (porosity $=0.56$ ); for various contact angles.

Figure 14. Variation of base heat flux with diameter of wires, for various superheats, porosity $=$ $0.56, T_{\text {inlet }}=T_{b o t}, T_{v}=298 \mathrm{~K}$ and $H=1$.

Figure 15. Variation of base heat flux with wick porosity at different superheats, $d=200 \mu \mathrm{m}, \Delta T=$ $2.5 \mathrm{~K}, T_{\text {inlet }}=T_{\text {bot }}, T_{v}=298 \mathrm{~K}$ and $H=1$. 
Table 1. Thermophys ical properties of water at $298 \mathrm{~K}$.

\begin{tabular}{|c|c|}
\hline Fluid & Water \\
\hline $\bar{M}(\mathrm{~kg} / \mathrm{kmol})$ & 18.01 \\
\hline$\rho\left(\mathrm{kg} / \mathrm{m}^{3}\right)$ & 998.2 \\
\hline$k(\mathrm{~W} / \mathrm{mK})$ & 0.6 \\
\hline$\mu(\mathrm{kg} / \mathrm{ms})$ & 0.00103 \\
\hline$C_{P}(\mathrm{~J} / \mathrm{kgK})$ & 4181.3 \\
\hline$h_{f g}(\mathrm{~kJ} / \mathrm{kg})$ & $2270 \times 10^{3}$ \\
\hline$d \sigma / d T(\mathrm{~N} / \mathrm{mK})$ & $-15 \times 10^{-5}$ \\
\hline
\end{tabular}


SIDE VIEW

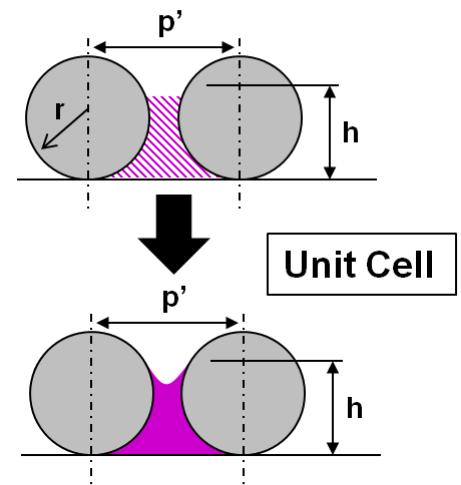

(a)

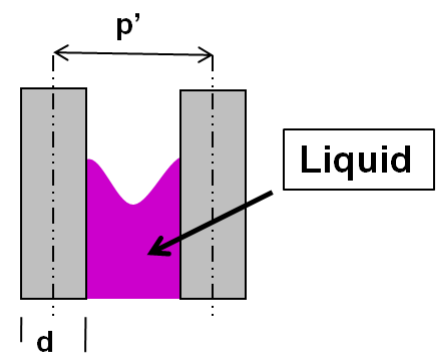

(c)
PLAN VIEW

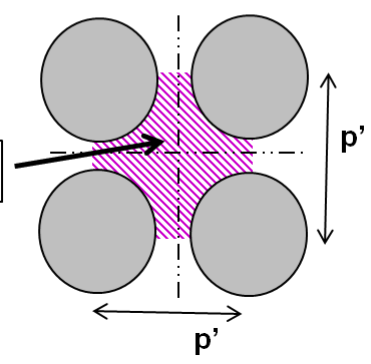

(b)

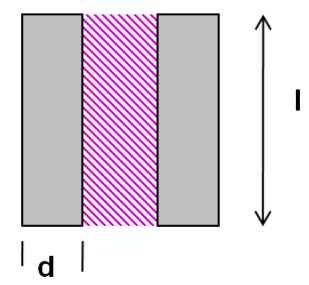

(d)

Figure 1. Side views of surface with (a) spheres (square packed) and horizontal wires, (c) vertical wires and parallel rectangular ribs, and plan views of surface with (b) spheres and wires (both square packed) and (d) horizontal w ires and rectangular ribs. The corresponding unit cell is also shown in each case. 


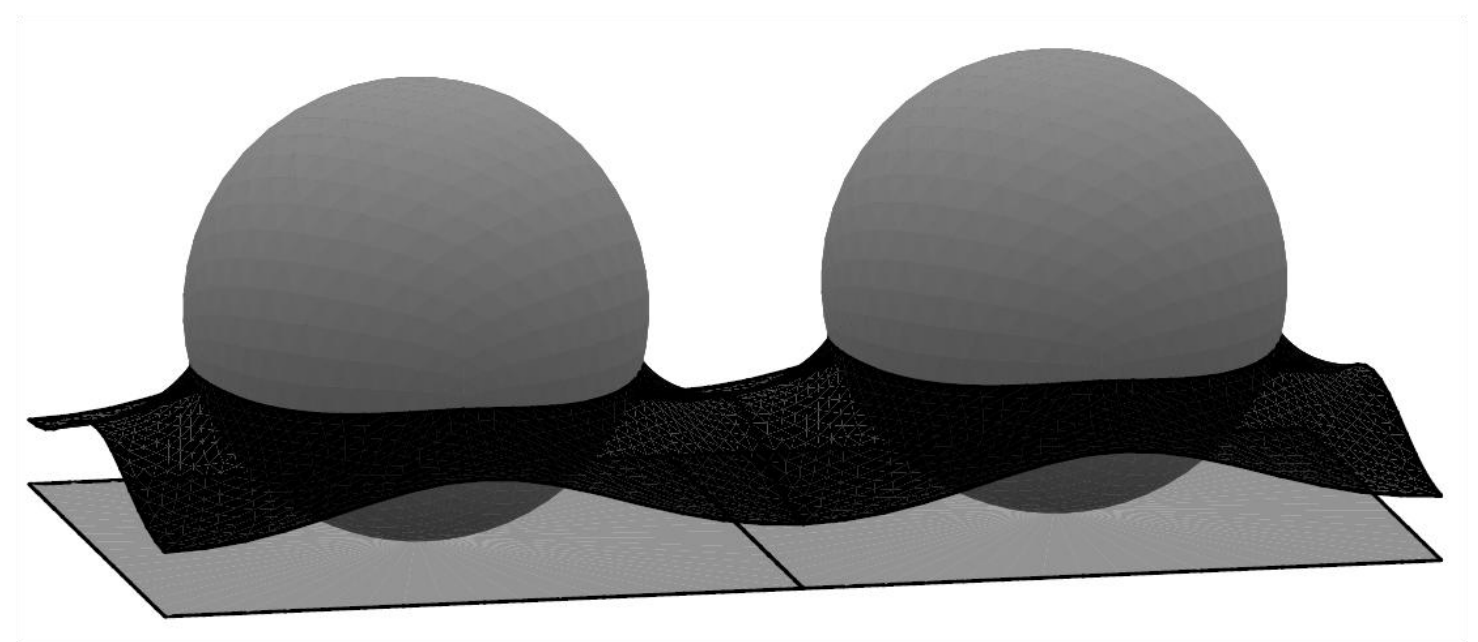

(a)

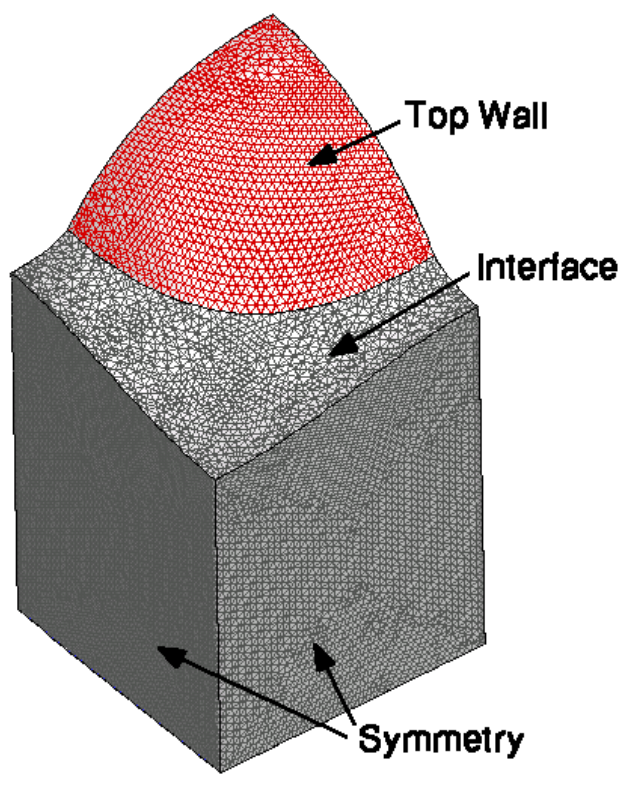

(b)

Figure 2. (a) Liquid meniscus shape for square-packed spheres, $H=1, d=1, \theta=15^{\circ}$; (b) surface mesh generated in GAMBIT for a unit cell representing square-packed spheres, porosity $=0.56, H=$ $1, d=1$ and $\theta=30^{\circ}$. 


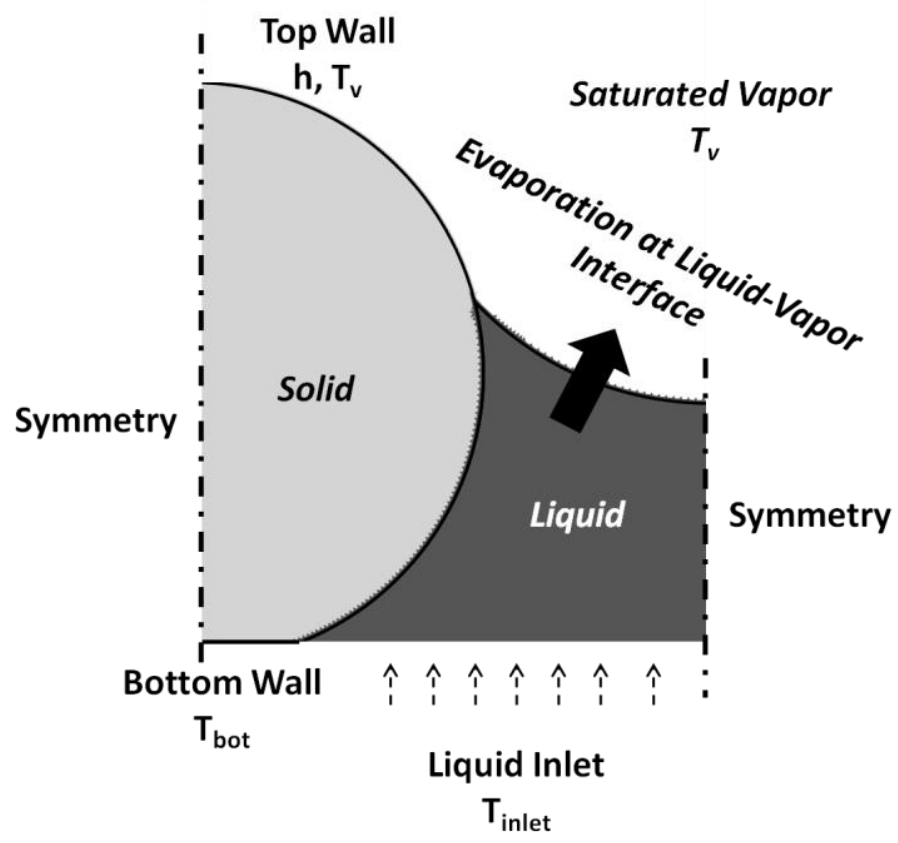

Figure 3. Illustration of boundary conditions for 2D liquid meniscus formed between horizontal wires. 


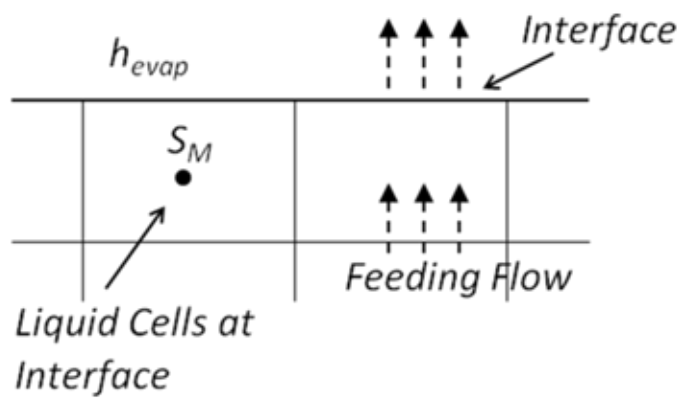

Figure 4. Implementation of evaporative cooling at liquid-vapor interface. A computational cell at the interface is shown. 


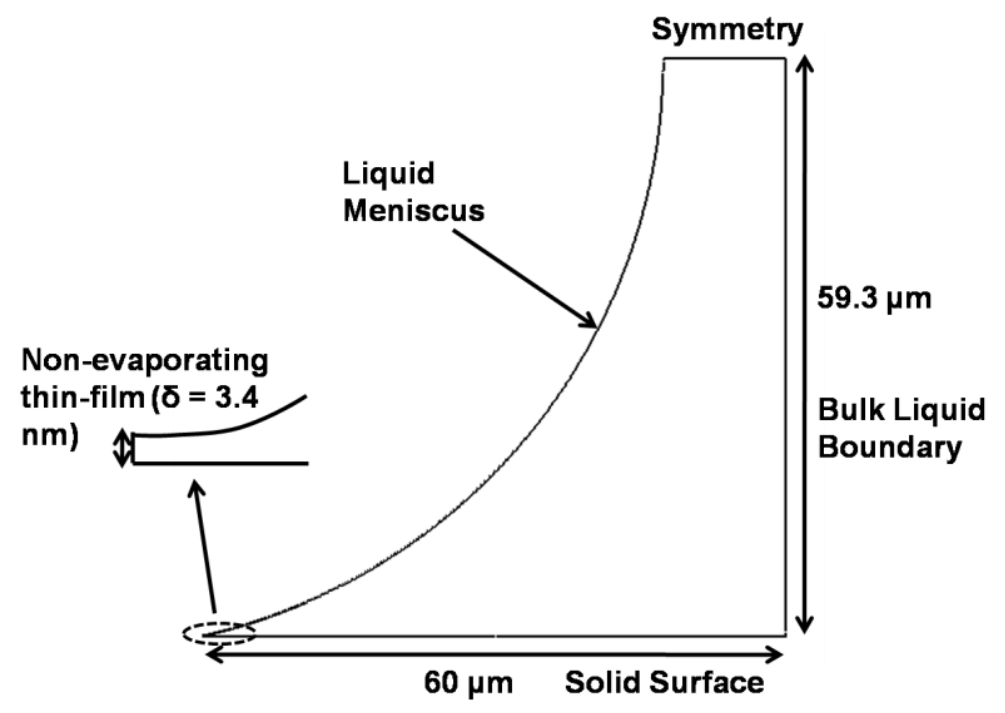

(a)

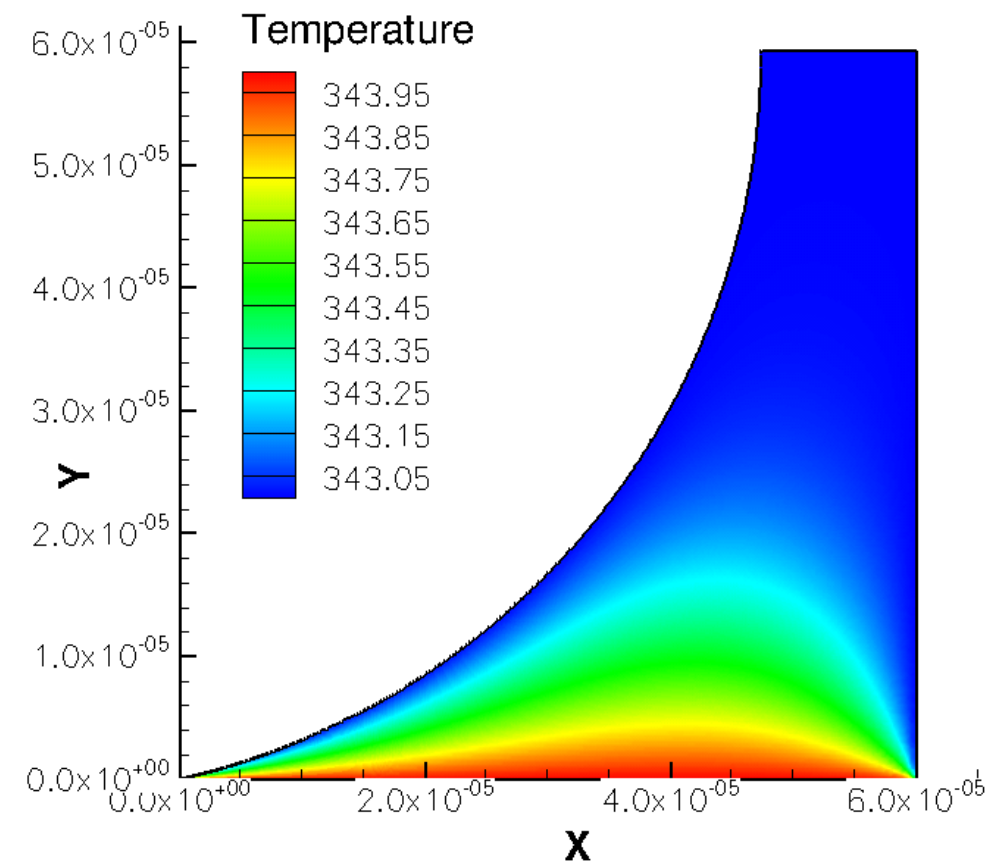

(b)

Figure 5. (a) Computational domain used for model validation of an octane meniscus formed inside a microchannel with $R^{*}=61 \mu \mathrm{m}$; (b) temperature contours in the domain for superheat $=1 \mathrm{~K}$ (solid surface temperature $=344 \mathrm{~K}$ and vapor temperature $=343 \mathrm{~K}$ ) 


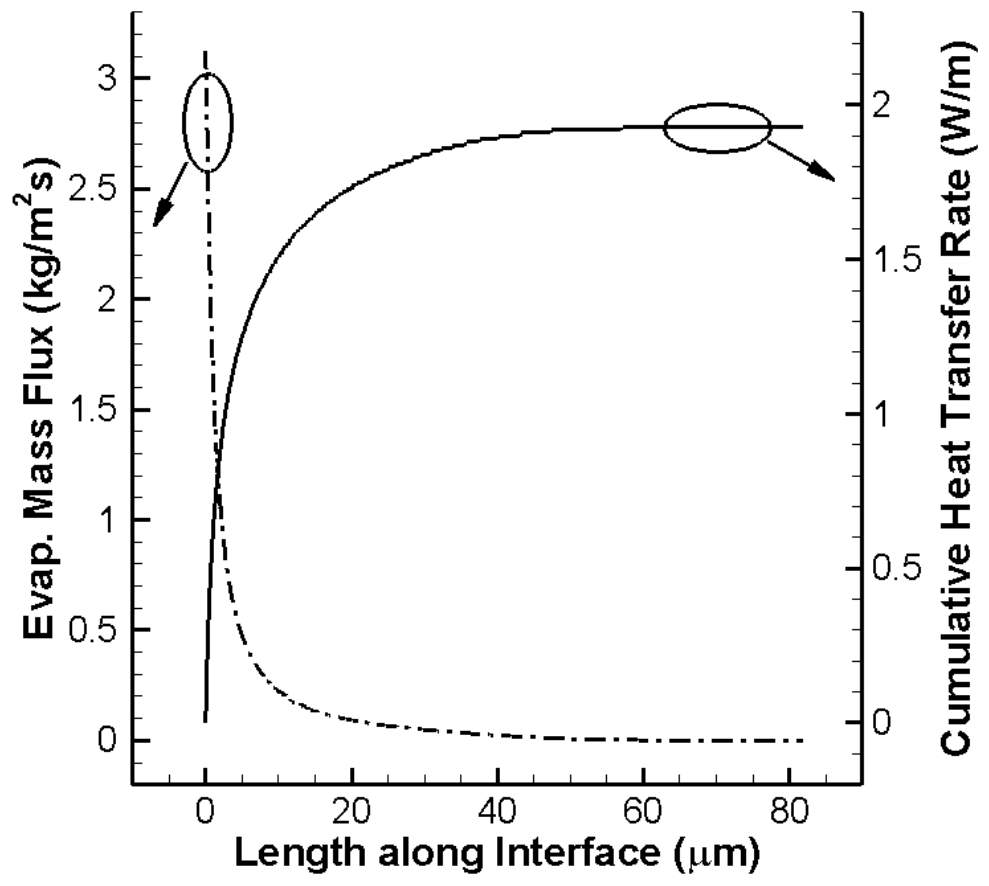

Figure 6. Evaporative mass flux and cumulative heat transfer rate at the octane meniscus formed in a microchannel. 


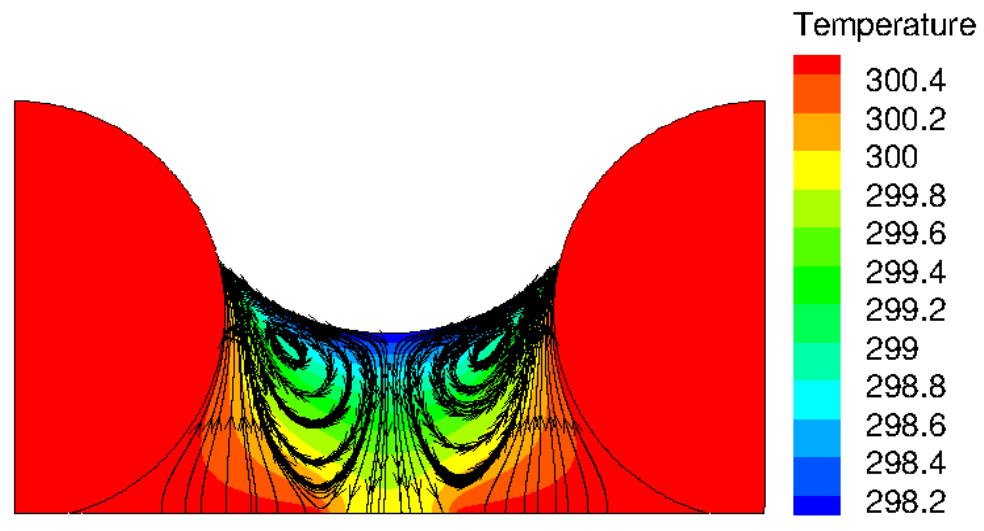

(a)

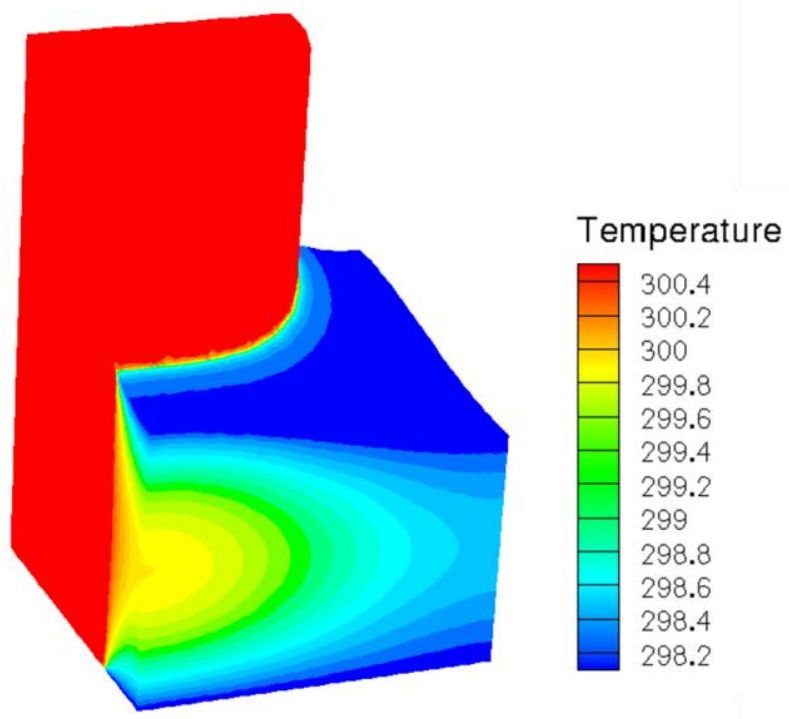

(b)

Figure 7. (a) Temperature contours and particle paths for 2D meniscus formed between horizontal wires, $d=200 \mu \mathrm{m}, T_{\text {inlet }}=300.5 \mathrm{~K}, T_{v}=298 \mathrm{~K}, T_{b o t}=300.5 \mathrm{~K}, \theta=15^{\circ}, p^{\prime}=356 \mu \mathrm{m}$ (porosity = 0.56 ), and (b) temperature contours on the interface, symmetry planes and top wall (refer Figure 3 ) for 3D meniscus formed in the pore of square-packed vertical microwires, $d=200 \mu \mathrm{m}, T_{\text {inlet }}=298$ $\mathrm{K}, T_{v}=298 \mathrm{~K}, T_{b o t}=300.5 \mathrm{~K}, \theta=60^{\circ}$ and $p^{\prime}=266 \mu \mathrm{m}$ (porosity $\left.=0.56\right)$. 


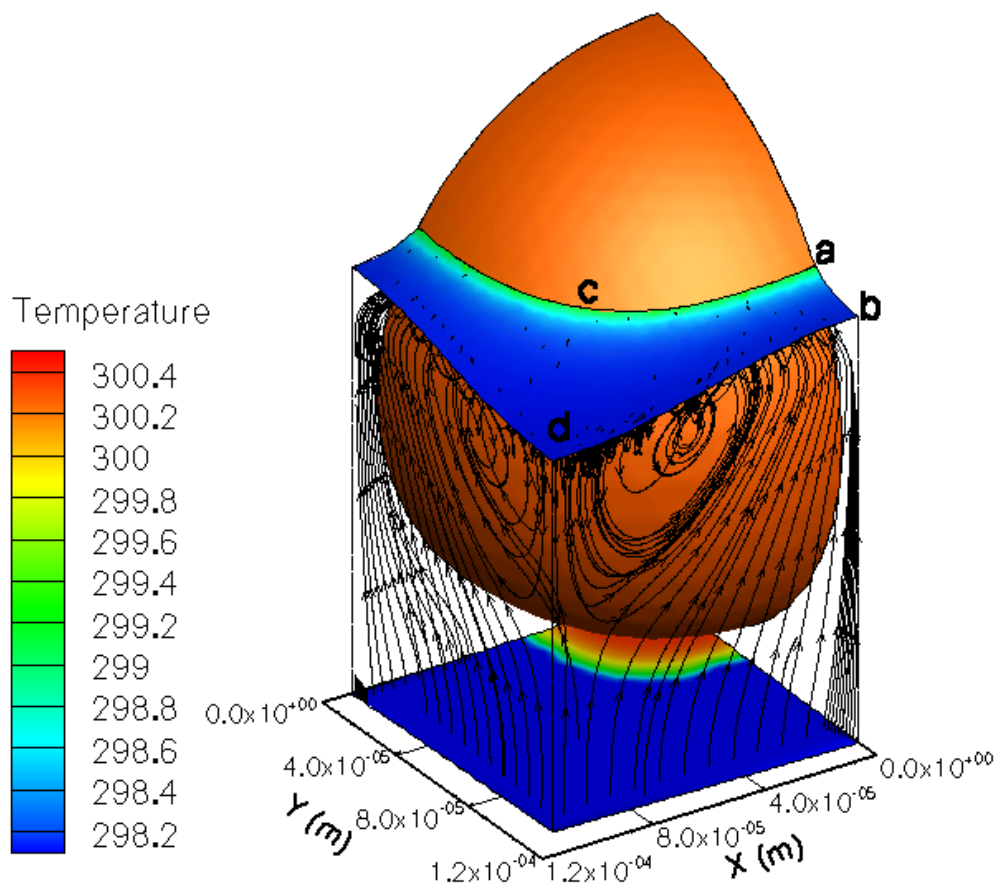

(a)

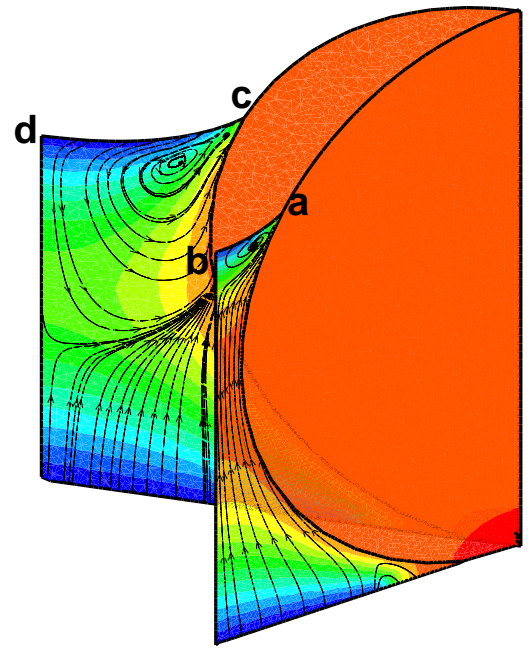

(b)

Figure 8. Temperature contours and particle paths for (a) 3D meniscus formed between squarepacked spheres, $d=200 \mu \mathrm{m}, T_{\text {inlet }}=298 \mathrm{~K}, T_{v}=298 \mathrm{~K}, T_{\text {bot }}=300.5 \mathrm{~K}, \theta=15^{\circ}, p^{\prime}=356 \mu \mathrm{m}$ (porosity $=0.56)$, and $(b)$ central $(c-d)$ and narrow $(a-b)$ planes. 


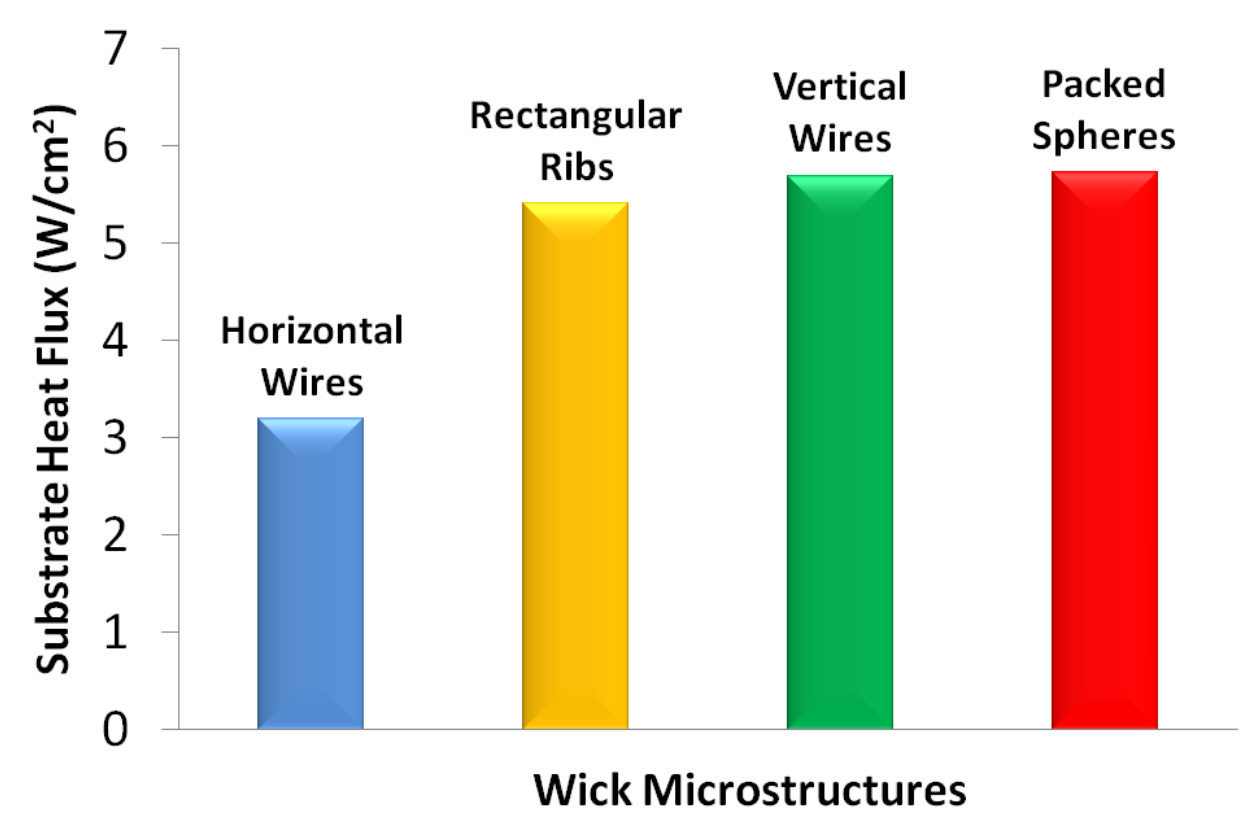

Figure 9. Comparison of microstructures for evaporative performance, porosity $=0.56, \theta=60^{\circ}$, $T_{\text {inlet }}=T_{\text {bot }}=300.5 \mathrm{~K}, T_{v}=298 \mathrm{~K}$. 


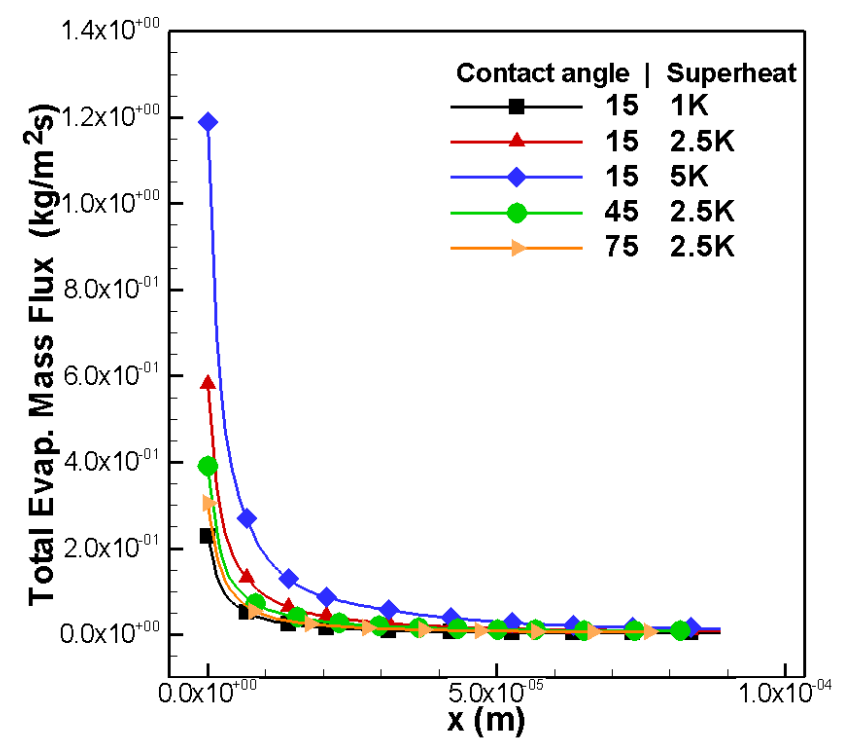

(a)

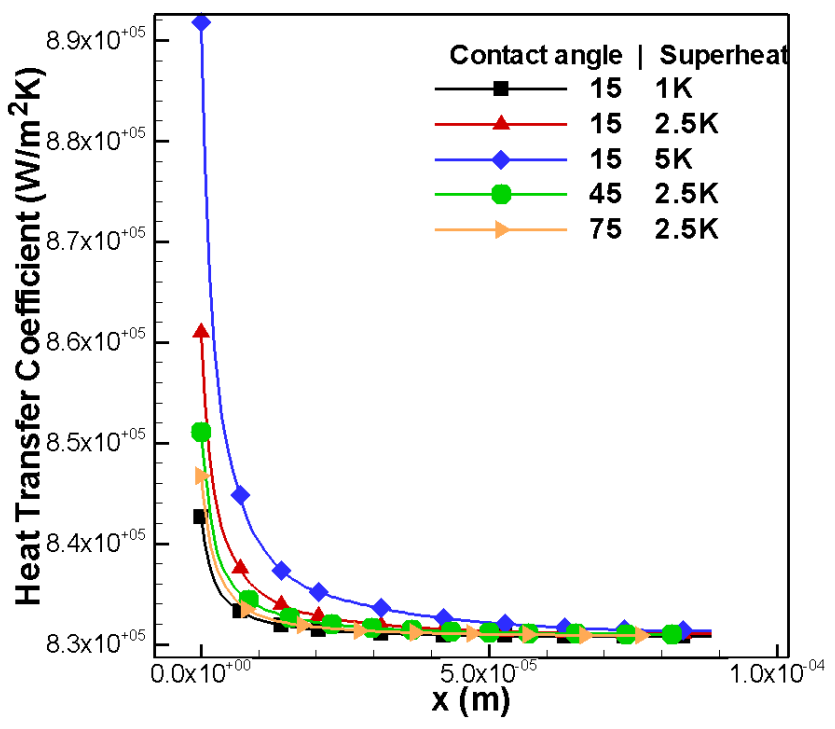

(b)

Figure 10. (a) Evaporative mass flux and (b) heat transfer coefficient on the interface, $d=200 \mu \mathrm{m}$, $T_{v}=298 \mathrm{~K}, p^{\prime}=356 \mu \mathrm{m}($ poros ity $=0.56)$. 


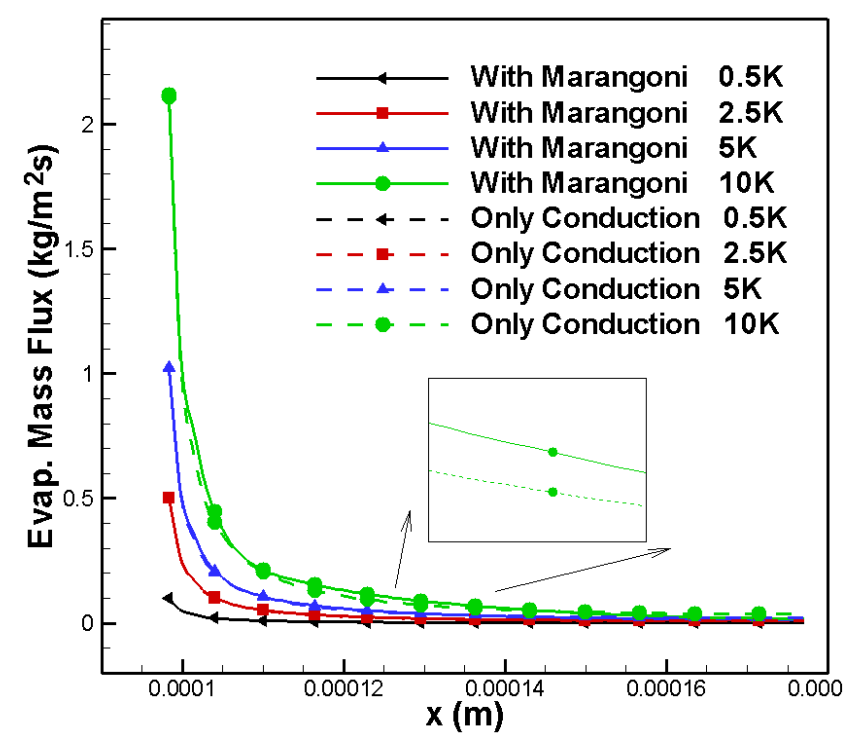

(a)

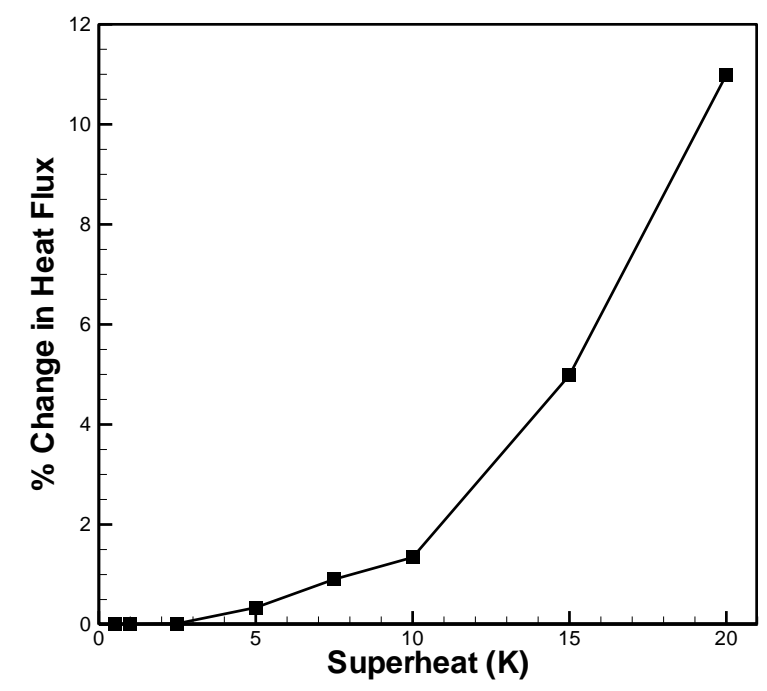

(b)

Figure 11. (a) Evaporative mass flux from the interface for pure conduction and Marangoni convection cases with different superheats, and (b) percentage change in total heat flux with and without Marangoni convection as a function of superheat, $d=200 \mu \mathrm{m}, T_{v}=298 \mathrm{~K}, \theta=15^{\circ}, p^{\prime}=$ $356 \mu \mathrm{m}$ (porosity $=0.56)$. 


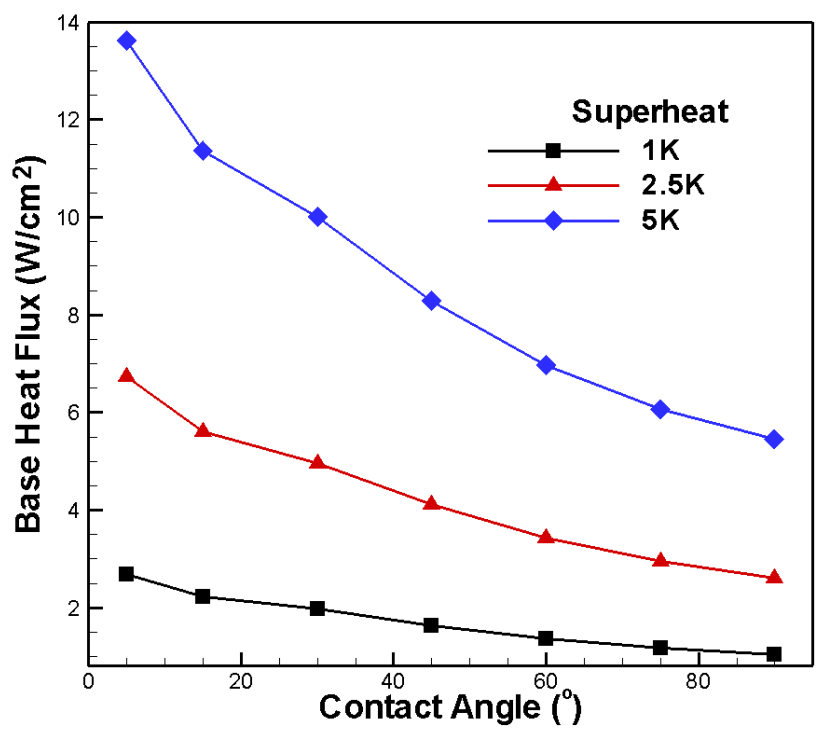

Figure 12. Variation of heat flux (based on base area) with solid-liquid contact angle, for three different superheats, $d=200 \mu \mathrm{m}, T_{v}=298 \mathrm{~K}, p^{\prime}=356 \mu \mathrm{m}$ (porosity $=0.56$ ). 


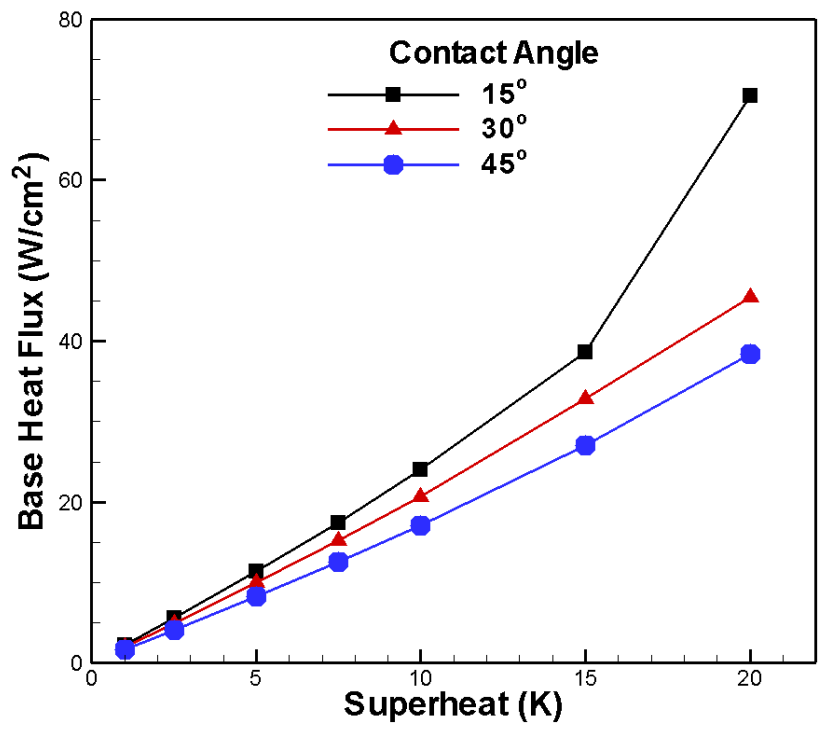

(a)

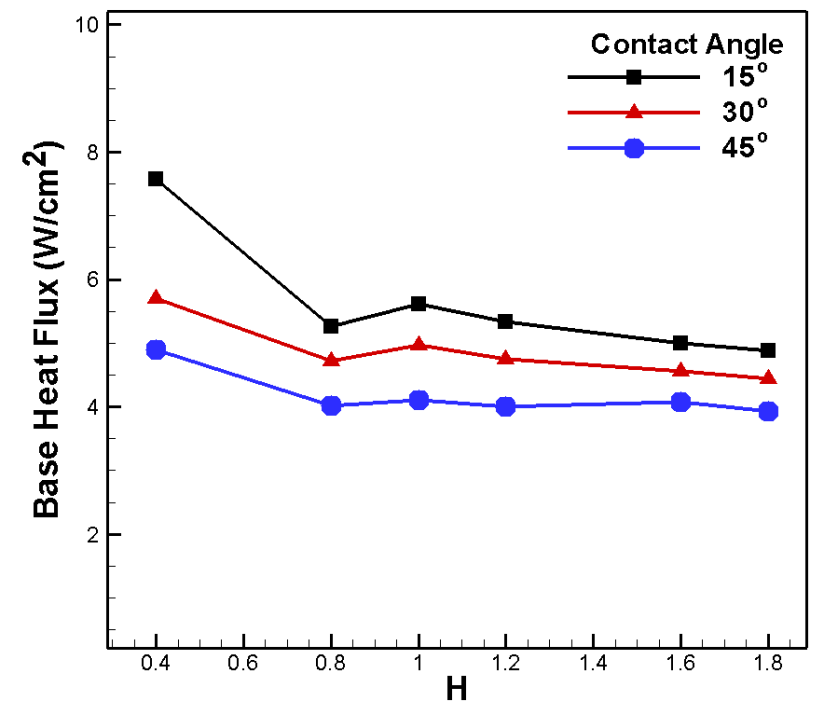

(b)

Figure 13. Variation of base heat flux for various contact angles with (a) superheat, $d=200 \mu \mathrm{m}$, $T_{\text {inlet }}=T_{b o t}, T_{v}=298 \mathrm{~K}, p^{\prime}=356 \mu \mathrm{m}$ (porosity $\left.=0.56\right), H=1$, and (b) meniscus level $(H), d=200$ $\mu \mathrm{m}, T_{\text {inlet }}=T_{\text {bot }}=300.5 \mathrm{~K}, T_{v}=298 \mathrm{~K}, p^{\prime}=356 \mu \mathrm{m}($ porosity $=0.56)$. 


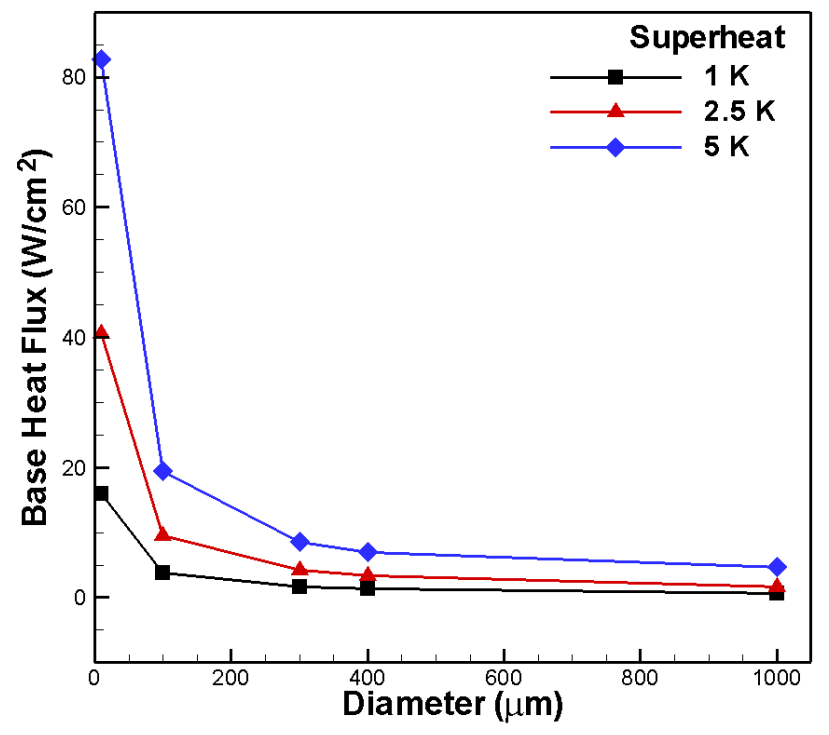

Figure 14. Variation of base heat flux with wire diameter for various superheats with porosity $=$ $0.56, T_{\text {inlet }}=T_{\text {bot }}, T_{v}=298 \mathrm{~K}$ and $H=1$. 


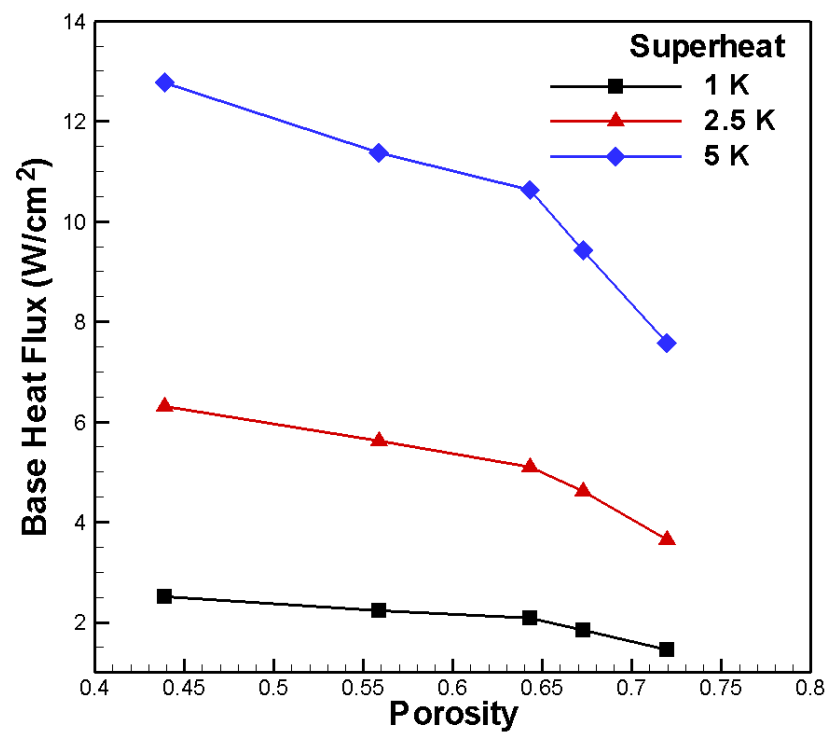

Figure 15. Variation of base heat flux with wick porosity at different superheats, $d=200 \mu \mathrm{m}, \Delta T=$ $2.5 \mathrm{~K}, T_{\text {inlet }}=T_{\text {bot }}, T_{v}=298 \mathrm{~K}$ and $H=1$. 